\title{
O CÓDIGO FLORESTAL BRASILEIRO: DIVERGÊNCIAS ENTRE A POLÍTICA E EVIDÊNCIAS CIENTÍFICAS
}

\author{
THE BRAZILIAN FOREST CODE: DIFFERENCES \\ BETWEEN POLITICS AND SCIENTIFIC EVIDENCE
}

\section{Valdir Lamim-Guedes}

Biólogo e Mestre em Ecologia pela Universidade Federal de Ouro Preto. Programa de Pós-Graduação lato sensu em Jornalismo Científico, Universidade Estadual de Campinas, Reitoria, Núcleo de Desenvolvimento da Criatividade, Laboratório de Estudos Avançados em Jornalismo (Labjor). Prédio V da Reitoria Piso 3, Cidade Universitária, CEP.: 13083970 - Campinas, SP - Brasil. E-mail dirguedes@yahoo.com.br

\begin{abstract}
RESUMO
O trâmite do Projeto de Lei que altera o Código Florestal no Senado Nacional foi acompanhado por uma intensa movimentação acadêmica, que incluiu a publicação de livros e artigos em periódicos científicos nacionais e internacionais. A comunidade acadêmica e os movimentos sociais colocaram-se contra as alterações no Código Florestal, contudo, boa parte das suas considerações não foi incluída no texto final. A aprovação da Lei Federal $n^{\circ}$. 12.651/2012 e da legislação complementar representa um grande retrocesso em relação à proteção da biodiversidade e manutenção de serviços ecossistêmicos. Neste texto são relatados alguns dos esforços da comunidade acadêmica e as consequências disto na política.

Palavras-chave: Legislação Ambiental. Biodiversidade. Serviços Ecossistêmicos. Política Ambiental.

ABSTRACT

The processing of the Bill amending the Forest Code on the Senate was accompanied by an intense academic movement, which included the books and articles' publications in national and international scientific journals. The academic community and social movements were against the changes in the Forest Code, however a large part of their considerations was not included in the final text. The Federal Law no. 12.651/2012 and complementary legislation represents a big step backwards in relation to the protection of biodiversity and maintenance of ecosystem services. In this paper are reported some of the efforts of the academic community and the consequences of this policy.
\end{abstract}

Keywords: Environmental Legislation. Biodiversity. Ecosystems Services. Environmental Policy.

\section{INTRODUÇÃO}

A existência de condições ambientais para uma vida saudável e continuidade da produção de alimentos passa pela manutenção de certos processos ambientais chamados, em conjunto, de 
serviços ambientais, entendidos como condições e processos através dos quais os ecossistemas naturais e as espécies que os compõem sustentam a vida humana (DAILY, 1997). Eles mantêm a biodiversidade e a produção de produtos ecossistêmicos, como madeira, fibras, alimentos e fármacos e seus precursores. O bem-estar de todas as populações humanas depende diretamente dos serviços fornecidos pelos ecossistemas (TEEB, 2010).

Por causa da degradação ambiental, cerca de $60 \%$ dos serviços ecossistêmicos da Terra foram degradados nos últimos 50 anos, sendo que a atuação humana foi a principal causa deste fenômeno (MEA, 2005). Há necessidade de medidas urgentes pelos tomadores de decisão para reverter o estágio atual de degradação ambiental. Dentro do quadro nacional, para estancar essa situação, as Âreas de Proteção Ambiental (APPs) e Reservas Legais (RLs) deveriam ser consideradas como parte fundamental do planejamento agrícola conservacionista das propriedades (SILVA et al., 2011), sobretudo promovendo a conservação da biodiversidade.

O uso adequado das terras é o primeiro passo para a preservação e conservação dos recursos naturais e para a sustentabilidade da agricultura. Deve, portanto, ser planejado de acordo com a sua aptidão, capacidade de sustentação e produtividade econômica, de tal forma que o potencial de uso dos recursos naturais seja otimizado, ao mesmo tempo em que sua disponibilidade seja garantida para as gerações futuras (SILVA et al., 2011).

Um dos grandes desafios da biologia da conservação, nas últimas décadas, é demonstrar que a perda de habitats, de interações ecológicas e de espécies gera um prejuízo (presente e futuro) que supera em muito os lucros advindos da exploração de recursos naturais e produção agrícola. No Brasil, o que vemos atualmente é uma tentativa de legalizar a perda de habitats, desconsiderando os argumentos científicos apresentados. Neste texto, são relatados a polêmica em torno do novo código florestal e alguns dos esforços da comunidade acadêmica brasileira, como a publicação de artigo e livros, e as consequências destes nos debates sobre as alterações no código florestal brasileiro.

\section{O NOVO CÓDIGO FLORESTAL BRASILEIRO}

As áreas protegidas não podem conservar a biodiversidade por si só, particularmente em paisagens dominadas por áreas antropizadas, em que há uma pressão intensa sobre os ambientes naturais por recursos alimentares, madeira e fibras (JOSE, 2012). Segundo Tim Benton, professor na Universidade de Leeds (Reino Unido), "no nível da paisagem, podemos gerenciar não apenas a terra agriculturável, mas também gerenciar as terras não agrícolas que são fundamentais para o funcionamento da atividade agrícola, porque mantêm os polinizadores, os inimigos naturais, os microclimas e assim por diante" (AGÊNCIA FAPESP, 2012). Neste sentido, é essencial que existam mecanismos previstos na legislação do país, a fim de permitir um manejo da paisagem de forma a favorecer a conservação da biodiversidade e a manutenção dos serviços ecossistêmicos. Este é o pano de fundo para alcançar os objetivos da Conversão sobre Diversidade Biológica (CDB), da qual o Brasil é signatário, em nível nacional e subnacional (estados e municípios).

O primeiro Código Florestal brasileiro foi instituído pelo Decreto no. 23.793, de 23 de janeiro de 1934, e revogado posteriormente pela Lei 4.771, de 15 de setembro de 1965, que instituiu o Código Florestal em esteve em vigor até maio de 2012, até a aprovação da Lei Federal $n^{\circ}$. 12.651/2012, sancionado em 28 de maio de 2012 (BRASIL, 2012a).

O Código Florestal de 1965, bem como todas as alterações subsequentes, levavam em consideração os conhecimentos científicos até então disponíveis (SILVA et al., 2011), situação diferente da atual, na qual as alterações no Código Florestal, justificadas para modernizar a legislação, foram discutidas e votadas ignorando a opinião da comunidade acadêmica e movimentos sociais (ZUCCO et al., 2011; LEITÃO, 2012). Sobre isto, Marcondes (2011) afirmou que o debate colocou no mesmo lado ambientalistas, cientistas e pesquisadores de diversas instituições, além de 
$80 \%$ da população. Ainda segundo esse autor, o relator do projeto de Lei, o Deputado Federal Aldo Rebelo, descreveu os opositores ao seu relatório como:

(...) detratores da pátria, gente a serviço do imperialismo internacional que não deseja ver o desenvolvimento do Brasil. Ignorou as contribuições oferecidas pela ciência através de documentos da Sociedade Brasileira para o Progresso da Ciência (SBPC) e da Associação Brasileira de Ciência (ABC), além de estudos desenvolvidos pelo Instituto de Pesquisas Econômicas Aplicadas (IPEA) (MARCONDES, 2011).

Depois de três anos de trâmite no Senado Nacional, o projeto foi aprovado com vetos da Presidenta da República Dilma Rousseff, tendo sido publicado no Diário Oficial da União dia 28 de maio de 2012 (BRASIL, 2012a), junto a uma medida provisória (MP), que contém a nova redação das partes do texto que foram vetadas pela Presidenta (BRASIL, 2012b).

Cabe aqui mencionar a movimentação por meio da internet em torno das polêmicas alterações no código florestal. Antes do veto parcial da Presidente Dilma, foi lançada a campanha "Veta Dilma", que reuniu mais de 1 milhão e 500 mil assinaturas, dando novo destaque internacional para esta situação (VIDAL e CARRINGOTN, 2012).

"Os vetos apenas evitaram o pior" (LEITÃO, 2012). O Comitê Brasil em Defesa das Florestas, coalizão formada por cerca de 200 organizações, da sociedade civil brasileira, contrárias às alterações no Código Florestal, avaliou que o veto parcial da Presidenta Dilma Rousseff foi insuficiente para o cumprimento de sua promessa de não anistiar desmatadores, nem de reduzir áreas de proteção (APPs e RLs) e, consequentemente, evitar a perda de muitos serviços ambientais. Ainda, contrariou interesses dos setores mais arcaicos do latifúndio, que queriam uma maior redução das áreas de proteção, por exemplo.

Ao vetar, no entanto, a Presidenta devolveu ao Congresso Nacional a decisão sobre as florestas, o que foi realizado somente após a Conferência das Nações Unidas sobre Desenvolvimento Sustentável (Rio+20) (COMITÊ BRASIL EM DEFESA DAS FLORESTAS E DO DESENVOLVIMENTO SUSTENTÁVEL, 2012). Uma decisão tomada para evitar mais polêmicas em um momento que o País era o centro das atenções do mundo em relação às questões ambientais, por causa da Rio+20.

No dia seguinte à publicação da nova Lei e da MP (29/maio/2012), foi publicada, também no Diário Oficial da União, uma alteração na MP, para corrigir um erro que incendiou os ambientalistas. No texto da MP publicado anteriormente, que restaura a essência do Código Florestal aprovado pelo Senado e posteriormente alterado pela Câmara, há um parágrafo que prevê que APPs em margem de rio possam ser recuperadas com espécies exóticas, o que é uma contradição com convenção da ONU sobre biodiversidade, da qual o Brasil é signatário (JORNAL DA CIÊNCIA, 2012).

O projeto original (PL 1876/99) do novo código, aprovado pelos parlamentares em maio do ano passado, já havia sofrido vetos parciais, que foram complementados pela Medida Provisória 571/12 (BRASIL, 2012b). Essa MP foi convertida em Lei em outubro de 2012, Lei 12.727/12 (BRASIL, 2012c), porém, após ser modificada pelos parlamentares, também teve nove itens vetados por Dilma, sob o argumento de não anistiar desmatadores e garantir a inclusão social no campo.

Os debates no senado sobre os novos vetos da Presidenta foram novamente utilizados pela bancada ruralista para exercer forte pressão e, assim, assegurar que seus interesses fossem preservados no texto da lei. Além destas movimentações no senado, existem algumas ações de inconstitucionalidade. A Procuradora-Geral da República (PRG) em exercício, Sandra Cureau, afirmou que "o processo legislativo foi dominado por propostas que tinham como pano de fundo um único objetivo: desonerar os proprietários rurais dos deveres referentes à proteção das florestas e, ainda, 'anistiar' ilegalidades antes cometidas" (ALTAFIN, 2013). A PRG considera 
inconstitucionais dispositivos que flexibilizam regras para áreas de preservação permanente (APP) e de reserva legal, além de normas que visam à regularização de áreas desmatadas ilegalmente.

Com isto, fica claro que uma versão final do Código Florestal ainda levará alguns meses para estar disponível. De fato, ao contrário da afirmação da Ministra Izabella Teixeira, esta ainda não é uma "página virada" (MENDES, 2012).

\section{OS BASTIDORES DO NOVO CÓDIGO FLORESTAL BRASILEIRO}

A atuação dos relatores e da bancada ruralista sobre as alterações no Código Florestal foi muito criticada, justamente por não levar em consideração as informações e alterações propostas pela comunidade acadêmica. Além disto, os defensores das alterações no Código Florestal não apresentaram informações científicas confiáveis, isto é, publicadas em periódico científico, com revisão às cegas dos manuscritos por pares e, de preferência, que este periódico seja de circulação internacional. Como foi denunciado pelo pesquisador Carlos Nobre, do INPE, "a reforma do Código Florestal aprovada pela Câmara dos Deputados aproveitou base científica de apenas um estudo, com conclusões duvidosas ou erradas e ainda não devidamente publicado" (SBPC, 2011).

O desenrolar dos debates sobre o Código Florestal demonstrou "uma fratura no sistema de representação política do Brasil” (LEITÃO, 2012). Grande parte da população brasileira, inclusive a comunidade acadêmica e, até mesmo, setores modernos do agronegócio - que compreendem a importância de alguns serviços ambientais para a produção agrícola -, não concordam com o texto aprovado pelas duas casas do Senado Nacional (LAMIM-GUEDES, 2011).

Essa situação é fruto da força do agronegócio, que está posicionado de forma hegemônica no Congresso Brasileiro e no próprio Governo Federal (VIDAL e CARRINGOTN, 2012). É fundamental a convergência das lutas populares e sociais contra o agronegócio para enfrentá-lo e avançar com as necessidades reais da sociedade brasileira (COMITÊ BRASIL EM DEFESA DAS FLORESTAS E DO DESENVOLVIMENTO SUSTENTÁVEL, 2012).

A participação da comunidade acadêmica neste processo envolve a produção de dados científicos confiáveis e a pressão sobre os políticos. Durante o trâmite do projeto de lei do novo código no Senado Nacional, algumas iniciativas da comunidade acadêmica foram de grande impacto, por exemplo, a publicação do livro $O$ Código e a Ciência, pela Sociedade Brasileira para o Progresso da Ciência e Academia Brasileira de Ciências (SILVA et al., 2011). Além disto, foram publicados vários artigos e cartas em periódicos científicos, como a carta Protect Brazil's land to avert disasters, na Revista Nature (ZUCCO et al., 2011) e um número especial da revista Biota Neotropica (Volume 10, número 4 de 2010). Inclusive publicações do próprio Governo, como o livro Áreas de Preservação Permanente e Unidades de Conservação \& Áreas de Risco: O que uma coisa tem a ver com a outra? (MMA, 2011) e o Comunicado do IPEA Código Florestal: implicações do PL 1876/99 nas áreas de reserva legal (IPEA, 2011).

Entre as conclusões do estudo do IPEA (IPEA, 2011), destaca-se o que seria mais adequado para a agropecuária nacional:

A proposta de isenção de área de RL tem como pressuposto o uso dessas áreas para exploração agropecuária convencional. Predomina no Brasil a agricultura monocultora de larga escala e a pecuária extensiva de gado bovino. $\mathrm{O}$ uso de pastagens para criação de bovinos ocupa, no Brasil, 74\% das áreas destinadas à agropecuária. O índice de lotação médio é de 1,08 cabeças por hectare, o que gera um valor efetivo por hectare de $\mathrm{R} \$ 496,00$. As lavouras temporárias ocupam $20,5 \%$ das áreas e geram uma produção valorada em R \$ 1.923,00/ha/ano. Soja, milho e cana-de-açúcar representam $75 \%$ das áreas de lavouras temporárias e seus valores de produção, por hectare/ano são, respectivamente, de $\mathrm{R} \$ 1.746,00, \mathrm{R} \$ 1.063,00$ e $\mathrm{R} \$ 2.740,00$. As lavouras permanentes ocupam 5,4\% das áreas, gerando um valor de produção de $\mathrm{R} \$ 4.246,00 / \mathrm{ha} / \mathrm{ano} 28$. 
Questiona-se se agropecuária convencional é a mais adequada para a agricultura familiar, em especial para os minifúndios, em função da pouca área disponível para o desenvolvimento da atividade econômica, mesmo que seja subtraída a reserva legal (IPEA, 2011).

Com esta conclusão, o IPEA (IPEA, 2011) deixou também a sua posição quanto à rentabilidade do sistema de produção agrícola do país. Este debate também inclui a contraposição entre conservação ambiental e produção agropecuária que será discutida a seguir.

\section{PRESERVAÇÃO DA VEGETAÇÃO NATURAL X PRODUÇÃO AGROPECUÁRIA}

Martinelli et al. (2010) argumentaram que não há falta de área já convertida para a expansão agrícola brasileira, portanto, não é verdadeira a dicotomia entre a preservação da vegetação natural e a produção agropecuária. Neste trabalho ficou claro que a alegação feita pelo deputado Aldo Rebelo, pela Senadora Kátia Abreu, entre outros, de que as alterações eram necessárias para manter a produção de alimentos torna-se falsa porque a área ocupada com alimentos consumidos diretamente pela população tem diminuído - com um aumento nas culturas ligadas à agroindústria e existe uma área significativa ocupada por pastagens ineficientes. Esta constatação é essencial quando se tratam das alterações do Código Florestal.

Conforme proposto pelos pesquisadores do Programa de Pesquisas em Caracterização, Conservação e Uso Sustentável da Biodiversidade do Estado de São Paulo (Programa BIOTA) (RODRIGUES et al., 2008), a averbação das áreas de RLs deve ser feita de forma a favorecer a conectividade entre remanescentes de vegetação nativa. Desta forma, seria possível criar uma rede de corredores de vegetação nativa interligando RLs e APPs, permitindo a manutenção dos serviços ecossistêmicos.

A ideia de desenvolvimento que embasa essa proposta de alteração do Código Florestal repete de certo modo a concepção expressa em "colher o fruto sem plantar a árvore" (HOLANDA, 1997), frase utilizada pelo historiador Sérgio Buarque de Holanda (1902-1982) para descrever o ideal de obter riquezas extraindo-as das novas terras descobertas nas grandes navegações, sem grandes investimentos nas colônias e sem preocupação com as consequências dessa exploração. Ou seja, algumas das normas em discussão consagram a obtenção de lucro fácil, sem maior preocupação com as consequências da atividade exploratória.

Como o argumento para a facilitação dos desmatamentos é a necessidade de aumentar a produção, pode-se dizer que a árvore será plantada, mas também será cortada logo após a colheita, impedindo que produza frutos para as próximas gerações. Isso porque a grande degradação ambiental incentivada pelo novo Código colocará em risco a própria produção agrícola e o bemestar da população no futuro (LAMIM-GUEDES, 2012).

Outro ponto que surge da dicotomia entre preservar e produção agrícola ou desenvolvimento, é a sugestão de que o desmatamento é essencial para a geração de renda e empregos. Um artigo publicado na revista norte-americana Science por uma equipe composta por pesquisadores do exterior e da ONG brasileira IMAZON apresentou uma forte evidência de o desmatamento não compensa (RODRIGUES et al., 2009). Nesse artigo, os autores fizeram uma análise do IDH (Índice de Desenvolvimento Humano) de municípios da região do arco do desmatamento na Amazônia. Eles encontraram que o IDH de áreas que estão sendo desmatadas é maior do que daquelas ainda florestadas, no entanto, após a criação do gado por uns 5-10 anos, o solo da região perde o pouco de fertilidade que tem e a produção cai, levando os criadores de gado a buscarem novas áreas. Resultado: o IDH começa a cair e logo já está em um nível bastante inferior aos das áreas florestadas.

Outra faceta deste problema é que isto vira um ciclo vicioso. O desmatamento abre espaço para novas pastagens que serão ocupadas pelo gado. Com o esgotamento do solo, novas pastagens 
têm que ser formadas em áreas que foram recém-desmatadas. Desta forma, sempre há novas áreas sendo abandonadas e ficando mais pobres do que antes quando florestadas.

\section{CONSIDERAÇÕES FINAIS}

A conservação das florestas tropicais, assim como outros tipos vegetacionais, não é exclusivamente um problema ecológico e cientistas podem somente prover soluções parciais (PUTZ e ZUIDEMA, 2008). Assim, como qualquer lei, o Código Florestal pode ser revisto - ou poderia ter sido - de forma abrangente para se adequar à realidade rural brasileira, mas principalmente, baseando-se também em avanços científicos que podem contribuir no aprimoramento permanente do processo de regulamentação ambiental (MARTINELLI et al. 2010).

A valorização da floresta, dos campos e da imensa biodiversidade do nosso território permitirá criar oportunidades para gerar riqueza de forma sustentável (social, econômica e ambientalmente). De acordo com essa perspectiva, é evidente que o Brasil não terá ganhos econômicos com as alterações no Código Florestal. As normas aprovadas implicarão significativas perdas de áreas com vegetação natural ainda existente nos biomas brasileiros e comprometerão compromissos assumidos pelo Brasil em acordos internacionais de redução de emissões de carbono para a atmosfera e de proteção à biodiversidade, respectivamente a Convenção-Quadro das Nações Unidas sobre Mudanças do Clima (CQNUMC) e a CDB e seus protocolos. Além disto, a grande degradação ambiental incentivada pelo novo código colocará em risco a própria produção agrícola e o bem-estar da população no futuro (LAMIM-GUEDES, 2012), e parte disto, deve-se a perda de serviços ambientais.

Nesse momento, em que a opinião de experimentados cientistas não está sendo considerada por uma grande parcela dos parlamentares, é muito adequado citar a observação sobre a degradação ambiental feita em 1817 pelo naturalista francês Auguste de Saint-Hilaire (1779-1853), quando viajava pela província de Minas Gerais: "É aí [nas florestas] que a natureza mostra toda a sua magnificência, é aí que ela parece desabrochar na variedade de suas obras; e, devo dizer com pesar, essas magníficas florestas foram muitas vezes destruídas sem necessidade" (SAINT-HILAIRE, 1974).

\section{REFERÊNCIAS}

AGÊNCIA FAPESP. Sustentabilidade agrícola requer abordagem sistêmica. 2012. Disponível em $<$ http://agencia.fapesp.br/15743>. Acesso Junho 2012.

ALTAFIN, I.G. PGR questiona constitucionalidade do novo Código Florestal. Agência Senado, 22/01/2013. Disponível em <http://www12.senado.gov.br/noticias/materias/2013/01/22/pgrquestiona-constitucionalidade-do-novo-codigo-florestal>. Acesso em janeiro de 2013.

BRASIL. Lei N ${ }^{\circ}$. 12.651, de 25 de maio de 2012. Brasília: Diário Oficial da União, CXLIX (102): 1-8. 2012a.

BRASIL. Medida Provisória No . 571, de 25 de maio de 2012. Brasília: Diário Oficial da União, CXLIX (102): 10-11. 2012b.

BRASIL. Lei No 12.727, de 17 de outubro de 2012 (Conversão da Medida Provisória nº 571, de 2012). Brasília: Diário Oficial da União, CXLIX (202): 1-3. 2012c. 
COMITÊ BRASIL EM DEFESA DAS FLORESTAS E DO DESENVOLVIMENTO SUSTENTÁVEL. Nota do Comitê em Defesa das Florestas e do Desenvolvimento Sustentável. 2012. Disponível em <http://www.florestafazadiferenca.org.br/ultimas-noticias/leia-nota-docomite-em-defesa-das-florestas-e-do-desenvolvimento-sustentavel>. Acesso em janeiro de 2013.

DAILY, G.C. Nature's services: Societal Dependence on Natural Ecosystems. Washington: Island Press, 1997. 392p.

HOLANDA, S.B.D. Raízes do Brasil. São Paulo: Companhia das Letras, 1997. 224p.

IPEA (Instituto de Pesquisas Econômicas Aplicadas). Código Florestal: implicações do PL 1876/99 nas áreas de reserva legal. Comunicados do IPEA, v. 96, 2011.

JORNAL DA CIÊNCIA. Código Florestal entra em vigor e já passa por alteração. 2012. Disponível em <http://www.jornaldaciencia.org.br/Detalhe.jsp?id=82603>. Acesso em janeiro de 2013.

JOSE, S. Agroforestry for conserving and enhancing biodiversity. Agroforestry Systems, Heidelberg (Alemanha), v. 85, p. 1-8, 2012.

LAMIM-GUEDES, V. A polinização e a agricultura sustentável. Ecodebate, 2011. Disponível em <http://www.ecodebate.com.br/2011/09/01/a-polinizacao-e-a-agricultura-sustentavel-artigo-devaldir-lamim-guedes/>. Acesso em janeiro de 2013.

LAMIM-GUEDES, V. Colher o fruto sem plantar a árvore. Ciência Hoje, Rio de Janeiro, v. 49, n.292, p. 60-61, 2012.

LEITÃO, M. O. O que Dilma fez com o código florestal. O Globo, 2012. Disponível em <http://oglobo.globo.com/pais/noblat/posts/2012/05/26/o-que-dilma-fez-com-codigo-florestal-pormiriam-leitao-447359.asp>. Acesso em janeiro de 2013.

MARCONDES, D. Código Florestal e o princípio da imprecaução. Carta Verde, 2011. Disponível em: <http://www2.cartacapital.com.br/blog/carta-verde/codigo-florestal-e-o-pr >. Acesso em novembro 2011.

MARTINELLI, L.A., JOLY, C.A., NOBRE, C.A.; SPAROVEK, G. A falsa dicotomia entre a preservação da vegetação natural e a produção agropecuária. Biota Neotropica, Campinas, v. 10, n.4, 2010.

MEA (MILLENNIUM ECOSYSTEM ASSESSMENT). Ecosystems and human well-being: synthesis. Washington: Island Press, 2005. 137p.

MENDES, P. Código Florestal é 'página virada', diz Izabella Teixeira. G1, 18/10/2012. Disponível em <http://g1.globo.com/natureza/noticia/2012/10/codigo-florestal-e-pagina-virada-diz-izabellateixeira.html >. Acesso em janeiro de 2013.

MMA (MINISTÉRIO DO MEIO AMBIENTE). Áreas de Preservação Permanente e Unidades de Conservação \& Áreas de Risco: O que uma coisa tem a ver com a outra? Brasília. 2011. 96p. 
PUTZ, F. E.; ZUIDEMA, P. A. Contribution of ecologists to tropical forest conservation. in: CARSON, W. P.; SCHNITZER, S. A. Tropical Forest community Ecology. Wiley-Blackwell. 2008, pp. 474-489.

RODRIGUES, A. S. L.; EWERS, R. M.; PARRY, L.; SOUZA JR., C.; VERÍSSIMO, A.; BALMFORD, A. Boom-and-Bust Development Patterns Across the Amazon Deforestation Frontier. Science, Nova York, v. 324, n. 12, p. 1435-1437, 2009.

RODRIGUES, R. R.; JOLY, C.A.; BRITO, M.C.W.; PAESE, A.; METZGER, J.O.; CASATTI, L.; NALON, M.A.; MENEZES, N.A.; BOLZANI, V.S.; BONONI, V.L.R. Diretrizes para a conservação e restauração da biodiversidade no estado de São Paulo. São Paulo: Instituto de Botânica, 2008. 248p.

SAINT-HILAIRE, A. Viagem pelo distrito dos diamantes e litoral do Brasil. Tradução de Leonam de Azeredo Penna. Itatiaia e Editora da Universidade de São Paulo, Belo Horizonte e São Paulo, [1833] 1974. 233p.

SBPC (SOCIEDADE BRASILEIRA PARA O PROGRESSO DA CIÊNCIA). 'Ciência' de apenas um estudo baseou alterações no Código Florestal. 2011. Disponível em

$<$ http://www.ecodebate.com.br/2011/07/21/ciencia-de-apenas-um-estudo-baseou-alteracoes-nocodigo-florestal/>. Acesso em janeiro de 2013.

SILVA, J.A.A.; NOBRE, A.D.; MANZATTO, C.V.; JOLY, C.A.; RODRIGUES, R.R.; SKORUPA, L.A.; NOBRE, C.A.; AHRENS, S.; MAY, P.H.; SÁ, T.D.A.; CUNHA, M.C.; RECH FILHO, E.L. O Código Florestal e a Ciência: contribuições para o diálogo. São Paulo:

Sociedade Brasileira para o Progresso da Ciência (SBPC); Academia Brasileira de Ciências (ABC). 2011. 124p.

TEEB (THE ECONOMICS OF ECOSYSTEMS AND BIODIVERSITY). TEEB for local and regional policy makers. Malta: Progress Press. 2010. 212p.

VIDAL, J.; CARRINGOTN, D. Petition calls on Brazilian president to veto 'catastrophic' forest code. The Guardian, 2012. Disponível em

<http://www.guardian.co.uk/environment/2012/may/11/petition-brazil-president-veto-forest-code>. Acesso em janeiro de 2013.

ZUCCO, C.A.; OLIVEIRA-SANTOS L.G.R.; FERNANDEZ, F.A.S. Protect Brazil's land to avert disasters. Nature, Londres, v. 470, p. 335, 2011. 